\title{
Methods for Measuring Risk for Type 2 Diabetes in Youth: The Oral Glucose Tolerance Test (OGTT)
}

\author{
Melinda E. Chen, $\mathrm{MD}^{1}$, Rebecca S. Aguirre, $\mathrm{MD}, \mathrm{PhD}^{2}$, and Tamara S. Hannon, $\mathrm{MD}$, MS \\ ${ }^{1}$ University of Nebraska Medical Center; ${ }^{2}$ Indiana University School of Medicine
}

Corresponding Author: Tamara S. Hannon

705 Riley Hospital Drive, Room 5960, Indianapolis, IN 46202

Email: tshannon@iu.edu

Keywords: insulin sensitivity; $\beta$-cell function; prediabetes; adolescent; pediatric

\begin{abstract}
Purpose of review: The oral glucose tolerance test (OGTT) is used both in clinical practice and research to assess glucose tolerance. In addition, the OGTT is utilized for surrogate measures of insulin sensitivity and the insulin response to enteral glucose, and has been widely applied in the evaluation of $\beta$-cell dysfunction in obesity, prediabetes, and type 2 diabetes. Here we review the use of the OGTT and the OGTT-derived indices for measurement of risk markers for type 2 diabetes in youth.

Recent findings: Advantages of using the OGTT for measures of diabetes risk include its accessibility and the incorporation of physiological contributions of the gut-pancreas axis in the measures of insulin response to glucose. Mathematical modeling expands the potential gains from the OGTT in physiology and clinical research. Disadvantages include individual differences in the rate of glucose absorption that modify insulin responses, imperfect control of the glycemic stimulus, and poor intraindividual reproducibility.
\end{abstract}

This is the author's manuscript of the article published in final edited form as:

Chen, M. E., Aguirre, R. S., \& Hannon, T. S. (2018). Methods for Measuring Risk for Type 2 Diabetes in Youth: the Oral Glucose Tolerance Test (OGTT). Current Diabetes Reports, 18(8), 51. https://doi.org/10.1007/s1 1892-018-1023-3 
Summary: Available research suggests the OGTT provides valuable information about the development of impaired glycemic control and $\beta$-cell function in obese youth along the spectrum of glucose tolerance.

\section{Introduction}

Type 2 diabetes (T2D) is a disorder characterized by reduced insulin sensitivity, worsening pancreatic islet $\beta$-cell function, progressive metabolic dysfunction, and dysglycemia.(1) Studies in youth have shown declining $\beta$-cell function along the spectrum of glucose tolerance, with obese youth having poorer $\beta$-cell function than lean youth, and youth with prediabetes and T2D having progressively deteriorating $\beta$ cell function. $(2,3)$ The underlying defects leading to dysglycemia in youth appear to differ from adults, which increases the need for research to better understand the pathophysiology and measureable risk factors for T2D in youth.(4)

Measuring risk for T2D in clinical research has focused on assessing $\beta$-cell function. Methods for measuring human $\beta$-cell function range in complexity from fasting laboratory measures to intravenous infusions of multiple stimulators of insulin release.(5) Selection of the optimum approach to assessing $\beta$ cell function includes consideration of the pertinent physiology, and also consideration of cost, resource availability, and participant burden (Table 1).

The oral glucose tolerance test (OGTT) is used both in clinical practice and research to assess glucose tolerance.(6) In addition, blood samples from the OGTT can be utilized for surrogate measures of insulin sensitivity, the insulin response to enteral glucose, and indices of $\beta$-cell function. Since the OGTT employs commonly available laboratory tests and clinical protocols, it is generally accessible for use in large-scale clinical and epidemiologic studies and has been widely applied in the evaluation of $\beta$-cell dysfunction in obesity, prediabetes, and T2D. $(7,8)$ Additionally, it is a useful tool for assessing the effects of treatment on measures of $\beta$-cell function. $(9,10)$ 
Here we review the pertinent physiology contributing to T2D, the necessary variables for measurement of $\beta$-cell function, and the use of the OGTT for measurement of $\beta$-cell function. We discuss common indices of insulin sensitivity and $\beta$-cell function calculated from OGTT-derived data, limitations of oral methods, and the use of modelling to augment interpretation of OGTT data.

\section{Physiological Considerations for Measuring Indices of Risk for T2D}

Under normal physiologic conditions, insulin secretion is stimulated, most notably by glucose, in a manner that maintains blood glucose within a normal physiological range. $(11,12)$ Intracellular mechanisms triggering the fusion of insulin granules to the cellular membrane and insulin release result in a biphasic insulin response.(11,12) The first-phase insulin response occurs quickly after circulating glucose concentrations increase, peaks within a few minutes, and subsides within 10 minutes.(13) The second-phase insulin response begins concurrently and consists of a slow and sustained increase in insulin concentrations.(13-15)

The development of T2D is characterized by poor insulin sensitivity (insulin resistance), poor or absent first-phase insulin, progressively worsening integrated insulin response, declining $\beta$-cell function (poorer insulin response adjusted for insulin sensitivity), and progressively worsening dysglycemia.(16) Insulin resistance may be defined as decreased responsiveness to the metabolic actions of insulin, including reduction in glucose disposal and the failure to suppress hepatic glucose production. When insulin sensitivity declines, a greater insulin response is needed to maintain normal glucose concentrations. Increased islet size and $\beta$-cell surface area is evident in pancreas samples from normoglycemic patients with insulin resistance who undergo pancreatoduodenectomies, suggesting that insulin resistance alters the $\beta$-cell even in the nondiabetic state.(17) 
Insulin clearance is an important physiological consideration for measuring the insulin response to glucose. Insulin undergoes first-pass metabolism in the liver, where much of the insulin is cleared from the blood stream. Rates of insulin clearance differ among individuals. Individuals with higher rates of insulin clearance have lower circulating insulin concentrations, as compared with individuals with low rates of insulin clearance.(18-20) Thus, peripheral blood samples for insulin concentrations can be an inaccurate indicator of the actual pre-hepatic insulin levels and are not representative of actual insulin secretion. C-peptide does not undergo first pass metabolism in the liver; thus, C-peptide concentrations are often also measured and serve as a correlate of insulin secretion and the insulin response. $(21,22)$ Circulating insulin levels, however, are appropriately utilized in measures of insulin action.

\section{OGTT Procedures and Measures of Glucose Tolerance}

A principle reason an OGTT is performed for both clinical and research purposes is to assess glucose tolerance. The OGTT is less frequently used for diagnostic purposes in the non-pregnant state since glycated hemoglobin (Hb A1c) has been endorsed for screening and diagnosis. $(6,23,24)$ Currently, clinical guidelines for youth who should have an OGTT for screening purposes include: patients with cystic fibrosis, annually, starting at age 10 years $(25,26)$; and pregnant females $(27)$. In the absence of these conditions, there are no clinical guidelines recommending routine OGTT testing for screening purposes in obese youth. A standard (1.75 g/kg body weight, up to $75 \mathrm{~g}$ ) OGTT is a minimal risk procedure that is applicable for large-scale screening in research protocols, or clinical diagnosis when there is continued weight gain and suspicion of progression of dysglycemia in patients with $\mathrm{HbA} 1 \mathrm{c}$ in the prediabetes range.(23) In cases where there is continued weight gain, no clinical improvement, and rising $\mathrm{HbA} 1 \mathrm{c}$ in the prediabetes range, using an OGTT to potentially make an earlier diagnosis of T2D may be beneficial, as youth are at risk for complications of diabetes, including diabetic ketoacidosis.(28) The 2-hr OGTT should be performed after a 10-12 hour overnight fast. A peripheral intravenous line may be inserted and maintained for frequent blood sampling. For clinical purposes, baseline fasting and 2-hr post ingestion blood samples are obtained for measurement of plasma glucose concentrations. 
For research purposes, additional blood samples are obtained, and insulin and C-peptide measures, as well as other pertinent hormones, are measured simultaneously.(29) Two (or more) baseline samples are obtained (commonly at -15 and 0 minutes) for measurements of plasma glucose and insulin/C-peptide. Insulin is secreted in a pulsatile and oscillatory pattern, thus taking the average of multiple (at least two) baseline measures is recommended.(11, 12) Thereafter, the flavored glucose is given orally and blood samples are obtained as necessary for the given protocol (commonly $+15,30,60,90$, and 120 minutes). More frequently sampling during the initial 30 minutes of the test and/or an extended duration of testing may be desired, particularly if mathematical modeling will be utilized to derive indices of insulin response to glucose.(30)

OGTT-derived standards for the diagnosis of T2D, as well as impaired fasting glucose and impaired glucose tolerance are identical for adults and youth.(6) In the non-pregnant state, normal fasting plasma glucose is $<100 \mathrm{mg} / \mathrm{dL}(6.11 \mathrm{mM})$. Fasting glucose levels between 100 and $125 \mathrm{mg} / \mathrm{dL}$ indicate impaired fasting glucose. Fasting glucose levels $\geq 126 \mathrm{mg} / \mathrm{dL}$ are consistent with diabetes. Two elevated readings on 2 separate days are needed to make a diagnosis. A random plasma glucose $\geq 200 \mathrm{mg} / \mathrm{dL}$ is consistent with diabetes if the individual has symptoms such as polyuria and polydipsia. During an OGTT (in the non-pregnant state), a 2-hour plasma glucose value of $<140 \mathrm{mg} / \mathrm{dL}$ is considered normal, $\geq 140$ and $<200$ $\mathrm{mg} / \mathrm{dL}$ is considered impaired glucose tolerance, and $\geq 200 \mathrm{mg} / \mathrm{dL}$ is considered diabetes.

While the diagnosis of prediabetes (either impaired fasting glucose, or impaired glucose tolerance, or both) is useful for broad diagnostic categorization and implies increased risk for T2D, there are pathophysiologic differences, with some overlap, in the two conditions. $(3,31)$ Youth with either isolated impaired fasting glucose or impaired glucose tolerance have both 1) reduced first-phase and second-phase insulin responses to intravenous glucose and 2) greater endogenous glucose production due to hepatic resistance to the action of insulin.(31) However, youth with isolated impaired fasting glucose appear to 
have superior peripheral insulin sensitivity compared with youth with impaired glucose tolerance.,25 Youth with the combination of impaired fasting glucose and impaired glucose tolerance have more substantial reductions in first- and second-phase insulin responses, and worse $\beta$-cell function, similar to youth with T2D. $(3,32)$

An additional point of consideration is poor reproducibility of OGTT data, especially in individuals at risk for T2D. $(8,29,33)$ In a study of 60 obese youth who underwent two separate OGTTs within 25 days, the percent positive agreement between the first and second OGTT was low for impaired fasting glucose (22\%) and impaired glucose tolerance (27\%).(29) Those who had discordant OGTT results had lower insulin response relative to insulin sensitivity, suggesting that variability on OGTT may be indicative of a higher risk of developing diabetes.

\section{Measures of Insulin Sensitivity from the Oral Glucose Tolerance Test}

The OGTT does not allow for direct measures of insulin sensitivity, but does allow for both fasting and glucose-stimulated surrogate measures of insulin sensitivity. As insulin sensitivity decreases, despite the increase in insulin concentrations, there is inadequate suppression of hepatic glucose output and fasting glucose concentrations increase. Decreased rates of glucose disposal associated with reduced peripheral (muscle and adipose tissue) insulin action are associated with greater glycemic excursions (per unit of insulin) during the OGTT. $(7,34)$ Indices of insulin sensitivity have been developed using both fasting and stimulated blood samples: inverse fasting insulin, homeostatic model assessment (HOMA, calculator at http://www.dtu.ox.ac.uk)(35), quantitative insulin sensitivity check index which is a permutation of $\operatorname{HOMA}\left(\mathrm{QUICKI}=1 /\left(\log \mathrm{I}_{0}+\log \mathrm{G}_{0}\right)\right)(36)$, and the combined plasma glucose and insulin excursions during the OGTT (whole body insulin sensitivity index, WBISI, or Matsuda-Defronzo index $=1000 / \sqrt{ }\left(\mathrm{G}_{0}\right.$ $\left.\left.I_{0}\right) *\left(G_{\text {mean }} I_{\text {mean }}\right)\right)$.(37) The composite WBISI is based on values of insulin $(\mu \mathrm{U} / \mathrm{mL})$ and glucose $(\mathrm{mg} / \mathrm{dL})$ obtained at baseline and 30 minutes during the OGTT. The WBISI correlated to measures of glucose 
disposal derived from the euglycemic-hyperinsulinemic clamp in youth $(r \sim 0.8) .(34,38)$ Other dynamic measures of insulin sensitivity obtained during an OGTT have been described by Stumvoll (39), Belfiore (40), and Gutt et al (41).

Of the fasting measures, inverse fasting insulin and HOMA-IS correlate reasonably well with the clamp insulin sensitivity index $(\mathrm{r}=0.6-0.7) .(5,42)$ Irrespective of glucose tolerance status, the simple calculation of 1 /fasting insulin correlates with clamp-measured insulin sensitivity comparably to HOMA or QUICKI.(34) Thus, the more complicated calculations, as well as OGTT-based surrogate estimates of insulin sensitivity, may be unnecessarily costly or cumbersome in cross-sectional, large-scale studies. Lower correlations between OGTT-derived indices and clamp insulin sensitivity compared with fasting indices may be related to the poor reproducibility of OGTT-derived measures in obese youth.(29)

While surrogate estimates of insulin sensitivity are useful in large-scale epidemiological or treatment studies, these measures may not be sensitive enough to detect changes in insulin sensitivity over time in longitudinal studies with relatively small number of participants. Correlations between longitudinal changes in surrogate indices of insulin resistance and more direct measures (hyperinsulinemic-euglycemic clamp or intravenous glucose tolerance test with minimal model-derived measures of insulin sensitivity) have rarely been formally evaluated. Xiang et al. followed a cohort of women with gestational diabetes in a longitudinal study and found changes in surrogate indices of insulin sensitivity to be less strongly correlated to changes in minimal model-derived measures, as compared to cross-sectional studies.(43) Moreover, it is inappropriate to use any surrogate measure of insulin sensitivity as a diagnosis of insulin resistance. There are no cut-points for "insulin sensitive" or "insulin resistant" states, as there is much overlap of these surrogate measures across quartiles of clamp-measured insulin sensitivity.(34) 


\section{Measures of Insulin Response from the Oral Glucose Tolerance Test}

The OGTT does not allow for direct measures of biphasic (first- and second-phase) insulin response.

First-phase insulin response is strictly measured in the first 10 minutes after administration of intravenous glucose, and not after enteral glucose.(13) Multiple factors associated with oral but not intravenous glucose administration make it impossible to distinguish a first-phase insulin response during the OGTT.

For example, the appearance of glucose in the circulation is relatively delayed, and gastrointestinal absorption and rates of rise in glucose concentrations vary among individuals. Thus, during the OGTT, the insulin responses may be defined as "early" and "late-phase" insulin responses to an oral glucose load.(5) The early-phase insulin response is generally accepted as the rise in insulin (C-peptide) above basal levels within 30 minutes of glucose load. $(5,44)$ The late-phase insulin response is less frequently used or defined, as it overlaps with the early-phase response. Insulin (C-peptide) area under the curve is more frequently utilized. $(34,38,44)$

To adequately sample varying insulin (C-peptide) concentrations frequent blood sampling is required and timing of the OGTT may be extended over the standard 2 hours.(30) In general, a 2-hour OGTT with blood samples at baseline (fasting) and 15 (or 10 and 20), 30, 60, 90, and 120 minutes have been most commonly used. Timing of samples during OGTT, however, should pay special attention to the first 30 minutes, while still accurately representing the glucose curve over the entire duration of the test. Though the first 30 minute period also includes the initial late-phase response, it encompasses the early-phase insulin response by definition. Despite its mixed character, the early-phase insulin response is measurably decreased with worsening dysglycemia, similar to first-phase insulin secretion measured by hyperglycemic clamp. $(7,45)$

The most common OGTT-derived indices of insulin response include the insulinogenic and C-peptide indices, both of which express incremental change in insulin and C-peptide levels, respectively, against change in glucose levels over the same time period (change in insulin or C-peptide divided by change in 
glucose from 0 to $30 \mathrm{~min}$ ).(44) However, there are circumstances where the measured insulin concentration at $30 \mathrm{~min}$ is lower than the insulin concentration at baseline, producing a negative value for the insulinogenic index.(46) This is likely due to measurement variability associated with the insulin assay at low concentrations of insulin. The prevalence of negative values is low overall, but increases in individuals with diabetes ( 3\%).(46) Worsening glycemic control results in more variability of glucose response to enteral stimuli and poorer reproducibility of OGTT results, and declining $\beta$-cell function makes it technically more difficult to measure insulin response and the measurement variability with the insulin assay becomes a dominant feature of the measurement itself .(47) The precision of glucose measures is better in individuals with lower glucose concentrations and measureable insulin response, compared with individuals with diminished insulin response .(47)

Total insulin response from the OGTT has been expressed integrated insulin responses as the incremental AUC insulin to glucose response, or the integrated insulin response. $(48,49)$ Integrated measures have been shown to have less variability than indices based on acute insulin responses.(50) However, integrated measures have the disadvantage of being a poorer reflection of the insulin response phase most dramatically affected early in the development of dysglycemia. Interpretation of the insulin response (either early phase or integrated response) separate without consideration of the prevailing insulin sensitivity is fraught with problems of interpretation, as insulin concentrations overlap in those with normal and impaired insulin response depending on the degree of insulin resistance and impairment of $\beta$ cell function.

The shape of the glucose response curve, monophasic versus biphasic, during the OGTT can also lend insight to physiological factors related to the development of diabetes.(51-55) A monophasic glucose response curve represents a gradual increase in glucose concentrations followed by a subsequent decrease in glucose.(52) Whereas a biphasic glucose response curve represents a curve with a second rise in 
glucose concentrations after the decline in glucose has occurred. In youth without diabetes, individuals with a monophasic glucose response curve appear to have greater risk factors for T2D, including lower clamp-derived hepatic and total body insulin sensitivity, and insulin response relative to insulin sensitivity (disposition index).(56)

\section{Expressing $\beta$-Cell Function using Measures from the Oral Glucose Tolerance Test}

Measures of $\beta$-cell function assess the ability of $\beta$ cells to generate an effective insulin response to a given stimulus, accounting for the prevailing insulin sensitivity. The mathematical equation for the square hyperbolic relationship linking insulin sensitivity and insulin response is commonly expressed as a “disposition index" (DI; insulin sensitivity $\times$ first-phase insulin response) (Figure 1).(57, 58) The DI is an expression of the acute insulin response adjusted for prevailing insulin sensitivity, and is utilized as a measure of $\beta$-cell function. A falling DI in an individual represents physiologic decompensation. $(59,60)$ To express a DI, one needs both measures of insulin sensitivity and stimulated insulin response.

Despite some limitations, the OGTT can be used to assess $\beta$-cell function. The use of OGTT variables to derive a DI (oral DI, oDI) is supported by mathematical evidence for an underlying hyperbolic relationship between surrogate measures of insulin sensitivity and insulin response from the OGTT.(8, 61) OGTT-derived measures of insulin response can be adjusted for insulin sensitivity using a surrogate measure, such as fasting insulin concentration or $\mathrm{HOMA} \% \mathrm{~S}$, or using a separate direct measurement.(5) Regardless, the oDI generally seems to have at least modest correlations to clamp-derived DI regardless of glucose tolerance category in youth $(60,62)$, is associated with poor glycemic control in youth(32), and is predictive of the development of dysglycemia in youth $(45,59)$ and diabetes in adults. $(8,63)$ 


\section{Gut-pancreas axis}

OGTT more closely reflects the integrated physiologic response to ingested stimuli than clamp or intravenous tolerance tests, as it allows assessments of the important physiological potentiating contributions of the gut-pancreas axis in the measure of insulin responses.(64) The incretin effect, referring to a higher insulin response to oral glucose than to intravenous glucose even at similar levels of glycemia, acknowledges the role of incretins such as glucagon-like peptide-1 (GLP-1) and glucosedependent insulinotropic peptide (GIP) which potentiate the insulin response to an oral glycemic stimulus. $(65,66)$ While both incretins offer long-term anti-apoptotic or proliferative benefits which are beyond the scope of this review, more salient to the OGTT is their effect on glycemic control - both incretins enhance insulin response, while GLP-1 also decreases glucagon secretion and enhances $\beta$-cell glucose sensitivity.(67) When an OGTT is combined with an intravenous test (IVGTT or hyperglycemic clamp), this allows comparisons of responses to enteral versus parenteral stimulation, enabling assessment of the contributions of the incretin effect to the insulin response to ingested glucose. $(68,69)$

Existing evidence in youth suggests a pattern of poorer incretin effect with worsening glycemic control.(70) In a study of 255 obese youth, Michaliszyn et al. found the ratio of OGTT-derived glucose sensitivity ( $\beta$-cell response to glucose) to hyperglycemic clamp-derived glucose sensitivity was significantly reduced in youth with impaired glucose tolerance versus those with normal glucose tolerance.(69) The incretin effect was not further diminished in youth with T2D. When compared to youth with normal glucose tolerance, youth with impaired glucose tolerance had 1) no difference in incretin concentrations, 2) similar hyperglycemic clamp-derived insulin responses, and 3) lower OGTTderived $\beta$-cell glucose responsiveness. These findings suggest that reduced incretin effect originates downstream of hormone production, and loss of the incretin effect may precede measurable declines in $\beta$ cell function. Variability in the incretin effect may also contribute to the increased intraindividual variability in OGTT results in youth with declining $\beta$-cell function. 


\section{Mathematical Modeling of OGTT-derived Data to Assess $\beta$-Cell Function}

The adaptation of mathematical minimal model methodologies for use with enteral stimuli has further extended our ability to utilize multiple-sample OGTT results.(71-73) Rather than relying on direct measurements of insulin sensitivity and insulin secretion, modeling employs mathematical descriptions of expected physiological behavior - glucose response to insulin and $\beta$-cell insulin (C-peptide) response to glucose - that are fitted to individual OGTT patient data. Modeling also provides the opportunity to mathematically investigate incretin augmentation of insulin secretion. $(69,73)$

Currently, two main models have been proposed and are frequently referenced. Both models separate $\beta$ cell responsivity into two distinct components -a response based on absolute glucose level (static secretion), and a response based on the rate of change of glucose (dynamic secretion). Mari, Ferrannini and colleagues have introduced a methodology wherein glucose data is first interpolated, then used with insulin or C-peptide data to describe the dependence of insulin response on glucose concentration.(73) Individual participant data is fitted to adjust parameter outputs. The authors have employed a 'potentiation factor' as necessary in creating an appropriate dose-response fit, and propose that this factor encompasses multiple factors affecting insulin response, including incretins. Cobelli and colleagues have introduced a methodology based on two simultaneous models. $(71,72)$ The glucose model describes the modulating effect of insulin on glucose disappearance from the oral load, while a C-peptide based model describes $\beta$-cell responsivity to glucose. This model postulates approximate physiological parallels, suggesting that dynamic insulin secretion is likely reflective of immediate insulin release, while static insulin secretion is likely related to insulin granule mobilization, thus correlating to early- and late-phase insulin secretion.(72) Similar models were originally formulated for use with intravenous glucose tolerance tests, but have since been adapted for use with OGTTs and mixed meal tests.(72, 74) They have been validated for reduced sampling schedules, and been shown to be a valuable tool in the adolescent population. $(4,45,71,72)$ 
The use of mathematical modeling to augment findings based on OGTT has several advantages. It allows multiple parameters (insulin action and insulin (C-peptide) response) to be derived while forgoing multiday testing. The distinction of dynamic and static insulin secretion allows for approximate localization of $\beta$-cell failure, with clinically meaningful correlates.(72) Moreover, the measured parameters and their DIs may offer better discrimination of changes along the spectrum of glycemic control, compared to calculated indices from the first 30 minutes of the OGTT.(4)

\section{Conclusions}

The OGTT is relatively simple, widely accessible, and incorporates the physiological contributions of the gut-pancreas axis in the measure of $\beta$-cell responses. Disadvantages of OGTT methodology for measuring $\beta$-cell function include differences in the rate of glucose absorption that can modify the observed response, imperfect control of the glycemic stimulus to insulin secretion, and higher intraindividual variability in glucose tolerance and measures of $\beta$-cell function compared with that seen with intravenous testing. Nevertheless, available research suggests that it provides valuable information about the development of impaired glycemic control, and those factors which create more variability can themselves be examined for greater insight into the pathophysiology of diabetes. Mathematical modeling is applicable to OGTT-derived data, thus expanding the potential gains from the OGTT in physiology and clinical research.

\section{Compliance with Ethical Standards}

\section{Conflict of Interest}

Melinda E. Chen, Rebecca S. Aguirre, and Tamara S. Hannon declare that they have no conflict of interest.

\section{Human and Animal Rights and Informed Consent}

This article does not contain any studies with human or animal subjects performed by any of the authors. 


\section{References}

Papers of particular interest, published recently, have been highlighted as:

* Of importance

** Of major importance

1. D'Adamo E, Caprio S. Type 2 diabetes in youth: epidemiology and pathophysiology. Diabetes Care 2011;34 Suppl 2:S161-5.

2. Hannon TS, Arslanian SA. The changing face of diabetes in youth: lessons learned from studies of type 2 diabetes. Ann N Y Acad Sci 2015;1353:113-37.

3. Bacha F, Lee S, Gungor N, Arslanian SA. From pre-diabetes to type 2 diabetes in obese youth: pathophysiological characteristics along the spectrum of glucose dysregulation. Diabetes Care 2010;33(10):2225-31.

**4. Chen ME, Chandramouli AG, Considine RV, Hannon TS, Mather KJ. Comparison of beta-Cell Function Between Overweight/Obese Adults and Adolescents Across the Spectrum of Glycemia.

Diabetes Care 2018;41(2):318-325.

This manuscript describes the comparison of adult and adolescent OGTT test results with model-derived and direct measures of insulin secretion and insulin sensitivity across a spectrum of glucose tolerance levels. Adolescents have much lower insulin sensitivity as compared with adults, whereas, adults have poorer beta-cell responses to glucose at earlier stages of glucose intolerance. These results may suggest different approaches to diabetes prevention in youths versus adults.

*5. Hannon TS, Kahn SE, Utzschneider KM, Buchanan TA, Nadeau KJ, Zeitler PS, et al. Review of methods for measuring beta-cell function: Design considerations from the Restoring Insulin Secretion (RISE) Consortium. Diabetes Obes Metab 2018;20(1):14-24.

A current review of intravenous and oral techniques for measuring beta-cell function.

6. 2. Classification and Diagnosis of Diabetes: Standards of Medical Care in Diabetes-2018. Diabetes Care 2018;41(Suppl 1):S13-S27.

7. Burns SF, Bacha F, Lee SJ, Tfayli H, Gungor N, Arslanian SA. Declining beta-cell function relative to insulin sensitivity with escalating OGTT 2-h glucose concentrations in the nondiabetic through the diabetic range in overweight youth. Diabetes Care 2011;34(9):2033-40.

8. Utzschneider KM, Prigeon RL, Faulenbach MV, Tong J, Carr DB, Boyko EJ, et al. Oral disposition index predicts the development of future diabetes above and beyond fasting and 2-h glucose levels. Diabetes Care 2009;32(2):335-41.

9. Effects of metformin, metformin plus rosiglitazone, and metformin plus lifestyle on insulin sensitivity and beta-cell function in TODAY. Diabetes Care 2013;36(6):1749-57.

10. Kahn SE, Lachin JM, Zinman B, Haffner SM, Aftring RP, Paul G, et al. Effects of rosiglitazone, glyburide, and metformin on beta-cell function and insulin sensitivity in ADOPT. Diabetes 2011;60(5):1552-60.

11. O'Meara NM, Sturis J, Van Cauter E, Polonsky KS. Lack of control by glucose of ultradian insulin secretory oscillations in impaired glucose tolerance and in non-insulin-dependent diabetes mellitus. J Clin Invest 1993;92(1):262-71.

12. Polonsky KS, Given BD, Van Cauter E. Twenty-four-hour profiles and pulsatile patterns of insulin secretion in normal and obese subjects. J Clin Invest 1988;81(2):442-8.

13. Ferrannini E, Pilo A. Pattern of insulin delivery after intravenous glucose injection in man and its relation to plasma glucose disappearance. J Clin Invest 1979;64(1):243-54.

14. Nesher R, Cerasi E. Modeling phasic insulin release: immediate and time-dependent effects of glucose. Diabetes 2002;51 Suppl 1:S53-9. 
15. O'Connor MD, Landahl H, Grodsky GM. Comparison of storage- and signal-limited models of pancreatic insulin secretion. Am J Physiol 1980;238(5):R378-89.

16. Kahn SE. The importance of the beta-cell in the pathogenesis of type 2 diabetes mellitus. Am J Med 2000;108 Suppl 6a:2S-8S.

17. Mezza T, Muscogiuri G, Sorice GP, Clemente G, Hu J, Pontecorvi A, et al. Insulin resistance alters islet morphology in nondiabetic humans. Diabetes 2014;63(3):994-1007.

18. Byrne MM, Sturis J, Polonsky KS. Insulin secretion and clearance during low-dose graded glucose infusion. Am J Physiol 1995;268(1 Pt 1):E21-7.

19. Haffner SM, Stern MP, Watanabe RM, Bergman RN. Relationship of insulin clearance and secretion to insulin sensitivity in non-diabetic Mexican Americans. Eur J Clin Invest 1992;22(3):147-53.

20. Jones CN, Pei D, Staris P, Polonsky KS, Chen YD, Reaven GM. Alterations in the glucosestimulated insulin secretory dose-response curve and in insulin clearance in nondiabetic insulin-resistant individuals. J Clin Endocrinol Metab 1997;82(6):1834-8.

21. Polonsky KS, Rubenstein AH. C-peptide as a measure of the secretion and hepatic extraction of insulin. Pitfalls and limitations. Diabetes 1984;33(5):486-94.

22. Polonsky KS, Rubenstein AH. Current approaches to measurement of insulin secretion. Diabetes Metab Rev 1986;2(3-4):315-29.

*23. Chan CL, Pyle L, Newnes L, Nadeau KJ, Zeitler PS, Kelsey MM. Continuous glucose monitoring and its relationship to hemoglobin A1c and oral glucose tolerance testing in obese and prediabetic youth. J Clin Endocrinol Metab 2015;100(3):902-10.

This manuscript describes the utility of HbA1c and OGTT in the evaluation of obese youth at risk for type 2 diabetes.

24. Roman R, Zeitler PS. Oral glucose tolerance testing in asymptomatic obese children: more questions than answers. J Clin Endocrinol Metab 2008;93(11):4228-30.

25. Moran A, Pillay K, Becker DJ, Acerini CL. ISPAD Clinical Practice Consensus Guidelines 2014. Management of cystic fibrosis-related diabetes in children and adolescents. Pediatr Diabetes 2014;15 Suppl 20:65-76.

26. Moran A, Brunzell C, Cohen RC, Katz M, Marshall BC, Onady G, et al. Clinical care guidelines for cystic fibrosis-related diabetes: a position statement of the American Diabetes Association and a clinical practice guideline of the Cystic Fibrosis Foundation, endorsed by the Pediatric Endocrine Society. Diabetes Care 2010;33(12):2697-708.

27. Moyer VA. Screening for gestational diabetes mellitus: U.S. Preventive Services Task Force recommendation statement. Ann Intern Med 2014;160(6):414-20.

28. Dabelea D, Rewers A, Stafford JM, Standiford DA, Lawrence JM, Saydah S, et al. Trends in the prevalence of ketoacidosis at diabetes diagnosis: the SEARCH for diabetes in youth study. Pediatrics 2014;133(4):e938-45.

29. Libman IM, Barinas-Mitchell E, Bartucci A, Robertson R, Arslanian S. Reproducibility of the oral glucose tolerance test in overweight children. J Clin Endocrinol Metab 2008;93(11):4231-7.

30. Dalla Man C, Campioni M, Polonsky KS, Basu R, Rizza RA, Toffolo G, et al. Two-hour sevensample oral glucose tolerance test and meal protocol: minimal model assessment of beta-cell responsivity and insulin sensitivity in nondiabetic individuals. Diabetes 2005;54(11):3265-73.

31. Cali AM, Bonadonna RC, Trombetta M, Weiss R, Caprio S. Metabolic abnormalities underlying the different prediabetic phenotypes in obese adolescents. J Clin Endocrinol Metab 2008;93(5):1767-73.

32. Bacha F, Pyle L, Nadeau K, Cuttler L, Goland R, Haymond M, et al. Determinants of glycemic control in youth with type 2 diabetes at randomization in the TODAY study. Pediatr Diabetes 2012;13(5):376-83.

33. Christophi CA, Resnick HE, Ratner RE, Temprosa M, Fowler S, Knowler WC, et al. Confirming glycemic status in the Diabetes Prevention Program: implications for diagnosing diabetes in high risk adults. J Diabetes Complications 2013;27(2):150-7. 
34. George L, Bacha F, Lee S, Tfayli H, Andreatta E, Arslanian S. Surrogate estimates of insulin sensitivity in obese youth along the spectrum of glucose tolerance from normal to prediabetes to diabetes. J Clin Endocrinol Metab 2011;96(7):2136-45.

35. Matthews DR, Hosker JP, Rudenski AS, Naylor BA, Treacher DF, Turner RC. Homeostasis model assessment: insulin resistance and beta-cell function from fasting plasma glucose and insulin concentrations in man. Diabetologia 1985;28(7):412-9.

36. Katz A, Nambi SS, Mather K, Baron AD, Follmann DA, Sullivan G, et al. Quantitative insulin sensitivity check index: a simple, accurate method for assessing insulin sensitivity in humans. J Clin Endocrinol Metab 2000;85(7):2402-10.

37. Matsuda M, DeFronzo RA. Insulin sensitivity indices obtained from oral glucose tolerance testing: comparison with the euglycemic insulin clamp. Diabetes Care 1999;22(9):1462-70.

38. Yeckel CW, Weiss R, Dziura J, Taksali SE, Dufour S, Burgert TS, et al. Validation of insulin sensitivity indices from oral glucose tolerance test parameters in obese children and adolescents. J Clin Endocrinol Metab 2004;89(3):1096-101.

39. Stumvoll M, Mitrakou A, Pimenta W, Jenssen T, Yki-Jarvinen H, Van Haeften T, et al. Use of the oral glucose tolerance test to assess insulin release and insulin sensitivity. Diabetes Care 2000;23(3):295-301.

40. Belfiore F, Iannello S, Volpicelli G. Insulin sensitivity indices calculated from basal and OGTTinduced insulin, glucose, and FFA levels. Mol Genet Metab 1998;63(2):134-41.

41. Gutt M, Davis CL, Spitzer SB, Llabre MM, Kumar M, Czarnecki EM, et al. Validation of the insulin sensitivity index (ISI $(0,120)$ ): comparison with other measures. Diabetes Res Clin Pract 2000;47(3):177-84.

42. Mather KJ, Hunt AE, Steinberg HO, Paradisi G, Hook G, Katz A, et al. Repeatability characteristics of simple indices of insulin resistance: implications for research applications. J Clin Endocrinol Metab 2001;86(11):5457-64.

43. Xiang AH, Watanabe RM, Buchanan TA. HOMA and Matsuda indices of insulin sensitivity: poor correlation with minimal model-based estimates of insulin sensitivity in longitudinal settings. Diabetologia 2014;57(2):334-8.

44. Phillips DI, Clark PM, Hales CN, Osmond C. Understanding oral glucose tolerance: comparison of glucose or insulin measurements during the oral glucose tolerance test with specific measurements of insulin resistance and insulin secretion. Diabet Med 1994;11(3):286-92.

45. Cali AM, Man CD, Cobelli C, Dziura J, Seyal A, Shaw M, et al. Primary defects in beta-cell function further exacerbated by worsening of insulin resistance mark the development of impaired glucose tolerance in obese adolescents. Diabetes Care 2009;32(3):456-61.

46. Faulenbach MV, Wright LA, Lorenzo C, Utzschneider KM, Goedecke JH, Fujimoto WY, et al. Impact of differences in glucose tolerance on the prevalence of a negative insulinogenic index. J Diabetes Complications 2013;27(2):158-61.

47. Hannon TS, Mather KJ. Measuring the transition to diabetes. J Diabetes Complications $2013 ; 27(2): 101-2$.

48. Hannon TS, Kirkman MS, Patel YR, Considine RV, Mather KJ. Profound defects in beta-cell function in screen-detected type 2 diabetes are not improved with glucose-lowering treatment in the Early Diabetes Intervention Program (EDIP). Diabetes Metab Res Rev 2014;30(8):767-76.

49. Jensen CC, Cnop M, Hull RL, Fujimoto WY, Kahn SE. Beta-cell function is a major contributor to oral glucose tolerance in high-risk relatives of four ethnic groups in the U.S. Diabetes 2002;51(7):2170-8.

50. Utzschneider KM, Prigeon RL, Tong J, Gerchman F, Carr DB, Zraika S, et al. Within-subject variability of measures of beta cell function derived from a $2 \mathrm{~h}$ OGTT: implications for research studies. Diabetologia 2007;50(12):2516-25.

51. Abdul-Ghani MA, Lyssenko V, Tuomi T, Defronzo RA, Groop L. The shape of plasma glucose concentration curve during OGTT predicts future risk of type 2 diabetes. Diabetes Metab Res Rev 2010;26(4):280-6. 
52. Tschritter O, Fritsche A, Shirkavand F, Machicao F, Haring H, Stumvoll M. Assessing the shape of the glucose curve during an oral glucose tolerance test. Diabetes Care 2003;26(4):1026-33.

53. Zhou W, Gu Y, Li H, Luo M. Assessing 1-h plasma glucose and shape of the glucose curve during oral glucose tolerance test. Eur J Endocrinol 2006;155(1):191-7.

54. Kim JY, Coletta DK, Mandarino LJ, Shaibi GQ. Glucose response curve and type 2 diabetes risk in Latino adolescents. Diabetes Care 2012;35(9):1925-30.

55. Nolfe G, Spreghini MR, Sforza RW, Morino G, Manco M. Beyond the morphology of the glucose curve following an oral glucose tolerance test in obese youth. Eur J Endocrinol 2012;166(1):10714.

*56. Kim JY, Michaliszyn SF, Nasr A, Lee S, Tfayli H, Hannon T, et al. The Shape of the Glucose Response Curve During an Oral Glucose Tolerance Test Heralds Biomarkers of Type 2 Diabetes Risk in Obese Youth. Diabetes Care 2016;39(8):1431-9.

This manuscript describes the usefullness of data collected at different time-points during a research OGTT as compared with clamp studies for evaluating risk for type 2 diabetes in obese youth.

57. Bergman RN, Ader M, Huecking K, Van Citters G. Accurate assessment of beta-cell function: the hyperbolic correction. Diabetes 2002;51 Suppl 1:S212-20.

58. Kahn SE, Prigeon RL, McCulloch DK, Boyko EJ, Bergman RN, Schwartz MW, et al. Quantification of the relationship between insulin sensitivity and beta-cell function in human subjects. Evidence for a hyperbolic function. Diabetes 1993;42(11):1663-72.

59. Giannini C, Weiss R, Cali A, Bonadonna R, Santoro N, Pierpont B, et al. Evidence for early defects in insulin sensitivity and secretion before the onset of glucose dysregulation in obese youths: a longitudinal study. Diabetes 2012;61(3):606-14.

60. Sjaarda L, Lee S, Tfayli H, Bacha F, Bertolet M, Arslanian S. Measuring beta-cell function relative to insulin sensitivity in youth: does the hyperglycemic clamp suffice? Diabetes Care 2013;36(6):1607-12.

61. Retnakaran R, Shen S, Hanley AJ, Vuksan V, Hamilton JK, Zinman B. Hyperbolic relationship between insulin secretion and sensitivity on oral glucose tolerance test. Obesity (Silver Spring) 2008;16(8):1901-7.

62. Retnakaran R, Qi Y, Goran MI, Hamilton JK. Evaluation of proposed oral disposition index measures in relation to the actual disposition index. Diabet Med 2009;26(12):1198-203.

63. Xiang AH, Kjos SL, Takayanagi M, Trigo E, Buchanan TA. Detailed physiological characterization of the development of type 2 diabetes in Hispanic women with prior gestational diabetes mellitus. Diabetes 2010;59(10):2625-30.

64. De Gaetano A, Panunzi S, Matone A, Samson A, Vrbikova J, Bendlova B, et al. Routine OGTT: a robust model including incretin effect for precise identification of insulin sensitivity and secretion in a single individual. PLoS One 2013;8(8):e70875.

65. Holst JJ, Gromada J. Role of incretin hormones in the regulation of insulin secretion in diabetic and nondiabetic humans. Am J Physiol Endocrinol Metab 2004;287(2):E199-206.

66. Muscelli E, Mari A, Natali A, Astiarraga BD, Camastra S, Frascerra S, et al. Impact of incretin hormones on beta-cell function in subjects with normal or impaired glucose tolerance. Am J Physiol Endocrinol Metab 2006;291(6):E1144-50.

67. Campbell JE, Drucker DJ. Pharmacology, physiology, and mechanisms of incretin hormone action. Cell Metab 2013;17(6):819-37.

68. Greenbaum CJ, Prigeon RL, D'Alessio DA. Impaired beta-cell function, incretin effect, and glucagon suppression in patients with type 1 diabetes who have normal fasting glucose. Diabetes 2002;51(4):951-7.

**69. Michaliszyn SF, Mari A, Lee S, Bacha F, Tfayli H, Farchoukh L, et al. beta-cell function, incretin effect, and incretin hormones in obese youth along the span of glucose tolerance from normal to prediabetes to type 2 diabetes. Diabetes 2014;63(11):3846-55. 
This manuscript describes OGTT-modeled beta-cell function and incretin effect in obese adolescents spanning the range of glucose tolerance. There is an impairment in incretin effect with decreasing glucose tolerance.

70. Aulinger BA, Vahl TP, Prigeon RL, D'Alessio DA, Elder DA. The incretin effect in obese adolescents with and without type 2 diabetes: impaired or intact? Am J Physiol Endocrinol Metab 2016;310(9):E774-81.

71. Breda E, Cavaghan MK, Toffolo G, Polonsky KS, Cobelli C. Oral glucose tolerance test minimal model indexes of beta-cell function and insulin sensitivity. Diabetes 2001;50(1):150-8.

*72. Cobelli C, Dalla Man C, Toffolo G, Basu R, Vella A, Rizza R. The oral minimal model method. Diabetes 2014;63(4):1203-13.

This review describes the methodology used to develop and utilize the oral minimal method, the measures it provides, and how it can provide novel insights regarding the regulation of postprandial metabolism.

73. Mari A, Schmitz O, Gastaldelli A, Oestergaard T, Nyholm B, Ferrannini E. Meal and oral glucose tests for assessment of beta -cell function: modeling analysis in normal subjects. Am J Physiol Endocrinol Metab 2002;283(6):E1159-66.

74. Rijkelijkhuizen JM, Girman CJ, Mari A, Alssema M, Rhodes T, Nijpels G, et al. Classical and model-based estimates of beta-cell function during a mixed meal vs. an OGTT in a population-based cohort. Diabetes Res Clin Pract 2009;83(2):280-8.

Figure 1. The hyperbolic relationship between insulin secretion and insulin sensitivity. Lean, insulinsensitive individuals require lower levels of insulinemia; obese, insulin-resistant but normoglycemic individuals compensate with an increased insulin response to glucose. Impaired glucose tolerance develops when the insulin response is insufficient to overcome insulin resistance, and the disposition index (DI), which is $\beta$-cell function relative to insulin sensitivity (insulin secretion $\times$ insulin sensitivity), declines. (From: Hannon and Arslanian, Annals of the New York Academy of Sciences. 2015;1353:11337, modified and used with permission) [2]. 